PP 33-38

www.iosrjournals.org

\title{
Courier partner selection for E-commerce business Using TOPSIS Method
}

\author{
B. Rajiv, M. Salunkhe \\ (Department of Production Engineering and Industrial Management, College of Engineering, Pune) \\ Email-salunkhems.pm@coep.ac.in
}

\begin{abstract}
In today's competitive business world, it is extremely important for decision makers to have access to decision support tools in order to make quick, right and accurate decisions. One of these decision making areas is courier service provider selection. Courier service provider selection is a multi - criteria decision making process that deals with the optimization of conflicting objectives such as quality, cost, and delivery time. If it is not supported by a system, this would be a complex and time consuming process. In spite of the fact that the term "Courier service provider selection" is commonly used in the literature, and many methods and models have been designed to help decision makers, few efforts have been dedicated to develop a system based on any of these methods. In this paper, Courier service provider selection decision support system based on the analytic hierarchy process (AHP) method which has been commonly used for multi-criteria decision making problems is proposed. To validate choice of the AHP model and also to validate the conceptual design of courier service provider selection decision support system, we conducted a case study as an example to determine best service Provider Company using TOPSIS model.
\end{abstract}

Keywords - Courier service provider selection, TOPSIS, AHP

\section{INTRODUCTION}

Determining the most suitable logistic service provider is an important problem to deal with when managing supply chain of a company. It is vital in enhancing the competitiveness of the company and has a positive impact on expanding the life span of the company.

One of the most important functions of the logistic department is the selection of efficient courier service providers, because it brings significant savings for the organization. While choosing the best provider, a logistic manager might be uncertain whether the selection will satisfy completely the demands of their organizations. The overall objective of the provider evaluation process is to reduce risk and maximize overall value to the purchaser.

\section{TOPSIS METHOD}

This study uses the TOPSIS method. A positive ideal solution maximizes the benefit criteria or attributes and minimizes the cost criteria or attributes, whereas a negative ideal solution maximizes the cost criteria or attributes and minimizes the benefit criteria or attributes. The TOPSIS method is expressed in a succession of six steps as follows:

Step 1: Calculate the normalized decision matrix. The normalized value ${ }^{r_{i j}}$ is calculated as follows:

$$
r_{i j}=x_{i j} \sqrt{\sum_{i-1}^{m} x_{i j}^{2}} \mathrm{i}=1,2, \ldots, \mathrm{m} \text { and } \mathrm{j}=1,2, \ldots, \mathrm{n} .
$$

Step 2: Calculate the weighted normalized decision matrix. The weighted normalized value $v_{i j}$ is calculated as follows:

$$
v_{i j}=r_{i j} \times w_{j} \mathrm{i}=1,2, \ldots, \mathrm{m} \text { and } \mathrm{j}=1,2, \ldots, \mathrm{n}
$$

Where $w_{j}$ is the weight of the $j^{\text {th }} \quad \sum_{j=1}^{n} w_{j}=1$ criterion or attribute and 


\section{Courier partner selection for E-commerce business Using TOPSIS Method}

Step 3: Determine the ideal ( $A^{*}$ ) and negative ideal $\left(A^{-}\right)$solutions.

$$
\begin{aligned}
& A^{*}=\left\{\left(\max _{i} v_{i j} \mid j \in C_{b}\right),\left(\min _{i} v_{i j} \mid j \in C_{c}\right)\right\}=\left\{v_{j}^{*} \mid j=1,2, \ldots, m\right\} \\
& A^{-}=\left\{\left(\min _{i} v_{i j} \mid j \in C_{b}\right),\left(\max _{i} v_{i j} \mid j \in C_{c}\right)\right\}=\left\{v_{j}^{-} \mid j=1,2, \ldots, m\right\}
\end{aligned}
$$

Step 4: Calculate the separation measures using the m-dimensional Euclidean distance. The separation measures of each alternative from the positive ideal solution and the negative ideal solution, respectively, are as follows:

$$
\begin{aligned}
& S_{i}^{*}=\sqrt{\sum_{j=1}^{m}\left(v_{i j}-v_{j}^{*}\right)^{2}, j=1,2, \ldots, m} \\
& S_{i}^{-}=\sqrt{\sum_{j=1}^{m}\left(v_{i j}-v_{j}^{-}\right)^{2}, j=1,2, \ldots, m}
\end{aligned}
$$

Step 5: Calculate the relative closeness to the ideal solution. The relative closeness of the alternative ${ }^{{ }^{i}}$ with respect to $A$ is defined as follows:

$$
R C^{*}{ }_{i}^{*}=\frac{S_{i}^{-}}{S_{i}{ }_{i}+S_{i}^{-}}, i=1,2, \ldots, m
$$

Step 6: Rank the preference order.

III.

EMPIRICAL EXAMPLE

Supplier selection for logistic are based on cost per courier service, cash on delivery service cost, insurance cost etc. (Price), Quality of the service based on lead time, reverse logistic, real time update of order, communication process \& pan India location serve. Reliability of logistic service based on management of the organization, capital \& revenue, product loss insurance coverage policy etc. \& Service of the logistic partner criteria based on product delivery, delivery time \& customization capability. Decision Hierarchy level (Table I) for the AHP method is categories based on importance level criteria \& weights are given based on the respective level of importance.

Table I

\section{DECISION HIERARCHY LEVEL}

\begin{tabular}{|c|c|c|c|c|}
\hline Level 0 & \multicolumn{4}{|c|}{ Supplier Selection Of Logistic Partner 100\% } \\
\hline Level 1 & Price 25\% & Quality 25\% & Reliability 25\% & Service 25\% \\
\hline \multirow{3}{*}{ Level 2 } & COD Price 8.3\% & $\begin{array}{c}\text { Pan India Location } \\
\text { Serve 8.3\% }\end{array}$ & $\begin{array}{c}\text { Management \& } \\
\text { Organization 8.3\% }\end{array}$ & $\begin{array}{c}\text { Communication } \\
8.3 \%\end{array}$ \\
\cline { 2 - 5 } & Insurance Price & Reverse Logistic & Capital \& Revenue & Delivery Lead Time \\
& $8.3 \%$ & Features 8.3\% & $8.3 \%$ & $8.3 \%$ \\
\cline { 2 - 5 } & Reverse Logistic & Product Delivery \& & Product Loss & Customization \\
& Price 8.3\% & COD Quality 8.3\% & $\begin{array}{c}\text { Ponce Coverage } \\
\text { Policy 8.3\% }\end{array}$ & Capability 8.3\% \\
\hline
\end{tabular}

\section{A. AHP Method}

Table II shows the resulting weights for the criteria based on pair wise comparisons. The resulting weights are based on the principal Eigen vector of the decision matrix. Pair wise comparison matrix of the main criteria with respect to the Goal.

Table II

DECISION MATRIX 
Courier partner selection for E-commerce business Using TOPSIS Method

\begin{tabular}{|c|c|c|c|c|c|c|c|c|}
\hline & FedEx & Gati & DTDC & Delhivery & Ecom & Aramex & Blue Dart & Procure \\
\hline FedEx & 1 & 6 & 5 & 5 & 2 & 2 & 5 & 2 \\
\hline Gati & 0.17 & 1 & 3 & 2 & 1 & 0.5 & 4 & 0.25 \\
\hline DTDC & 0.2 & 0.33 & 1 & 0.33 & 0.2 & 0.17 & 2 & 0.17 \\
\hline Delhivery & 0.2 & 0.5 & 3 & 1 & 0.33 & 0.33 & 1 & 0.25 \\
\hline Ecom & 0.5 & 1 & 5 & 3 & 1 & 0.5 & 4 & 0.2 \\
\hline Aramex & 0.5 & 2 & 6 & 3 & 2 & 1 & 4 & 0.5 \\
\hline Blue Dart & 0.2 & 0.25 & 0.5 & 1 & 0.25 & 0.25 & 1 & 0.25 \\
\hline Procure & 0.5 & 4 & 6 & 4 & 5 & 2 & 4 & 1 \\
\hline
\end{tabular}

Number of comparisons $=28$

Consistency Ratio CR $=6.0 \%$

Principal Eigen value $=8.584$

Eigenvector solution: 6 iterations, delta $=8.6 \mathrm{E}-9$

Table III shows the scale of AHP module, scale of AHP module decision based on testing the actual service of courier partner \& noted down the analysis point based on weight scaling done.

Table III

SCALE OF AHP CALCULATION

\begin{tabular}{|c|c|c|c|c|}
\hline Name Of Vendor & Price & Quality & Reliability & Service \\
\hline FedEx & 114 & 179 & 142 & 142 \\
\hline Gati & 125.97 & 160 & 124 & 133 \\
\hline DTDC & 118.56 & 148 & 119 & 136 \\
\hline Delhivery & 107 & 139 & 116 & 129 \\
\hline Ecom Express & 110.81 & 156 & 121 & 127 \\
\hline Aramex & 116.85 & 167 & 126 & 139 \\
\hline Blue Dart & 131.1 & 177 & 136 & 143 \\
\hline Procure & 142.5 & 148 & 112 & 126 \\
\hline
\end{tabular}

\section{B.AHP Rank Method}

We use only rank of each alternative under each criterion in AHP rank method.

Table IV.

RESULT OF RANK METHOD

\begin{tabular}{|c|c|c|c|c|c|c|}
\hline Name Of Vendor & Price & Quality & Reliability & Service & $\begin{array}{c}\text { weighted } \\
\text { rank }\end{array}$ & conclusion \\
\hline FedEx & 3 & 1 & 1 & 2 & 1.75 & 1 \\
\hline Gati & 6 & 4 & 4 & 5 & 4.75 & 4 \\
\hline DTDC & 5 & 6 & 6 & 4 & 5.25 & 6 \\
\hline Delhivery & 1 & 8 & 7 & 6 & 5.5 & 7 \\
\hline Ecom Express & 2 & 5 & 5 & 7 & 4.75 & 4 \\
\hline Aramex & 4 & 3 & 3 & 3 & 3.25 & 3 \\
\hline Blue Dart & 7 & 2 & 2 & 1 & 3 & 2 \\
\hline Procure & 8 & 6 & 8 & 8 & 7.5 & 8 \\
\hline
\end{tabular}

From the above AHP method supplier selection for the logistic partner is FedEx based on the pair wise comparison of other logistic partner with respect to price, quality, reliability \& service of the courier, thus validation of the above AHP result with TOPSIS module as follow. 
Courier partner selection for E-commerce business Using TOPSIS Method

C.TOPSIS Method

Table V shows the collected data of courier service provider \& converted to scale.

Table V

THE COLLECTED SCALE

\begin{tabular}{|c|c|c|c|c|}
\hline Name Of Vendor & Price & Quality & Reliability & Service \\
\hline Fedex & 113.6 & 179 & 142 & 142 \\
\hline Gati & 125.97 & 160 & 124 & 133 \\
\hline DOTZOT (DTDC) & 118.56 & 148 & 119 & 136 \\
\hline Delhivery & 107 & 139 & 116 & 129 \\
\hline Ecom Express & 110.808 & 156 & 121 & 127 \\
\hline Aramex & 116.85 & 167 & 126 & 139 \\
\hline Blue Dart & 131.1 & 177 & 136 & 143 \\
\hline \multirow[t]{3}{*}{ Procure } & 142.5 & 148 & 112 & 126 \\
\hline & Min & Max & Max & Max \\
\hline & $25.00 \%$ & $25.00 \%$ & $25.00 \%$ & $25.00 \%$ \\
\hline Ideal & 107 & 179 & 142 & 143 \\
\hline the worst & 142.5 & 139 & 112 & 126 \\
\hline
\end{tabular}

All criterions to maximize - it is a condition of TOPSIS method. So, the minimizing criterions had to be converted.

Table VI

THE NORMALIZED MATRIX WITH SUPPLIER AND EVALUATION CRITERIA

\begin{tabular}{|c|c|c|c|c|}
\hline Name Of Vendor & Price & Quality & Reliability & Service \\
\hline FedEx & 28.9 & 179 & 142 & 142 \\
\hline Gati & 16.53 & 160 & 124 & 133 \\
\hline (DTDC) & 23.94 & 148 & 119 & 136 \\
\hline Delhivery & 35.5 & 139 & 116 & 129 \\
\hline Ecom Express & 31.692 & 156 & 121 & 127 \\
\hline Aramex & 25.65 & 167 & 126 & 139 \\
\hline Blue Dart & 11.4 & 177 & 136 & 143 \\
\hline Procure & 0 & 148 & 112 & 126 \\
\hline Normalized & 68.80472 & 452.0221 & 353.1487 & 380.48 \\
\hline
\end{tabular}

Table VII

CRITERIA WEIGHTING

\begin{tabular}{|c|c|c|c|c|}
\hline $\begin{array}{c}\text { Weighted } \\
\text { Normalized matrix }\end{array}$ & Price & Quality & Reliability & Service \\
\hline FedEx & 0.105007 & 0.099 & 0.100524 & 0.093303 \\
\hline Gati & 0.060061 & 0.088491 & 0.087782 & 0.08739 \\
\hline DTDC & 0.086985 & 0.081854 & 0.084242 & 0.089361 \\
\hline Delhivery & 0.128988 & 0.076877 & 0.082118 & 0.084761 \\
\hline Ecom Express & 0.115152 & 0.086279 & 0.085658 & 0.083447 \\
\hline Aramex & 0.093199 & 0.092363 & 0.089198 & 0.091332 \\
\hline Blue Dart & 0.041422 & 0.097893 & 0.096277 & 0.09396 \\
\hline Procure & 0 & 0.081854 & 0.079287 & 0.08279 \\
\hline \multicolumn{5}{|l|}{} \\
\hline Ideal & 0.128988 & 0.099 & 0.100524 & 0.09396 \\
\hline Worst & 0 & 0.076877 & 0.079287 & 0.08279 \\
\hline
\end{tabular}

The (positive ideal) ideal $(\mathrm{A}+)$ and (negative ideal) worst $(\mathrm{A}-)$ solutions are determined using Equations (V) and (VI). The results are shown in Table VII.The separation of each alternative solution is calculated using Table (VIII) and (IX). The final results are shown in Table X. 
Table VIII

POSITIVE IDEAL SOLUTIONS

\begin{tabular}{|c|c|c|c|c|}
\hline From Ideal & Price & Quality & Reliability & Service \\
\hline FedEx & 0.023981 & 0 & 0 & 0.000657 \\
\hline Gati & 0.068927 & 0.010508 & 0.012743 & 0.006571 \\
\hline DTDC & 0.042003 & 0.017145 & 0.016282 & 0.004599 \\
\hline Delhivery & 0 & 0.022123 & 0.018406 & 0.009199 \\
\hline Ecom Express & 0.013836 & 0.012721 & 0.014866 & 0.010513 \\
\hline Aramex & 0.03579 & 0.006637 & 0.011327 & 0.002628 \\
\hline Blue Dart & 0.087567 & 0.001106 & 0.004248 & 0 \\
\hline Procure & 0.128988 & 0.017145 & 0.021238 & 0.01117 \\
\hline
\end{tabular}

Table IX

NEGATIVE IDEA SOLUTIONS

\begin{tabular}{|c|c|c|c|c|}
\hline From worst & Price & Quality & Reliability & Service \\
\hline FedEx & 0.105007 & 0.022123 & 0.021238 & 0.010513 \\
\hline Gati & 0.060061 & 0.011614 & 0.008495 & 0.004599 \\
\hline DTDC & 0.086985 & 0.004978 & 0.004955 & 0.006571 \\
\hline Delhivery & 0.128988 & 0 & 0.002832 & 0.001971 \\
\hline Ecom Express & 0.115152 & 0.009402 & 0.006371 & 0.000657 \\
\hline Aramex & 0.093199 & 0.015486 & 0.009911 & 0.008542 \\
\hline Blue Dart & 0.041422 & 0.021017 & 0.01699 & 0.01117 \\
\hline Procure & 0 & 0.004978 & 0 & 0 \\
\hline
\end{tabular}

The result of the ranking of approaches is derived using Equations (X) (Table X). The first alternative is considered as the best maximization of expected benefits for the courier partner to concentrate the business resources and strengthen logistic strategy.

Table X

RESULTS OF CLOSENESS COEFFICIENT AND RANK

\begin{tabular}{|c|c|c|c|c|}
\hline dit & di- & ci & Conclusion & Name Of Vendor \\
\hline 0.023989 & 0.1098977 & 0.820821 & 1 & FedEx \\
\hline 0.071182 & 0.061932 & 0.465255 & 6 & Gati \\
\hline 0.048419 & 0.0875154 & 0.643803 & 5 & DTDC \\
\hline 0.030212 & 0.1290344 & 0.810277 & 3 & Delhivery \\
\hline 0.026168 & 0.1157126 & 0.815561 & 2 & Ecom Express \\
\hline 0.038211 & 0.095378 & 0.713961 & 4 & Aramex \\
\hline 0.087676 & 0.0507038 & 0.366409 & 7 & Blue Dart \\
\hline 0.132316 & 0.0049776 & 0.036255 & 8 & Procure \\
\hline
\end{tabular}

\section{CONCLUSION}

Logistics service provider selection process becomes increasingly important in today's complex environment. The selection process involves the determination of quantitative and qualitative factors to select the best possible provider. Decision-makers face up to the uncertainty and vagueness from subjective perceptions and experiences in the decision-making process. The decision criteria are cost of service, financial performance, 
Courier partner selection for E-commerce business Using TOPSIS Method operational performance, and long- term relationships. The analysis helped the company to structure the problem with its differing aspects rather than only financial considerations. As a result of this study alternative first (FedEx) is determined as the best logistics service provider which has the highest priority weight.

This study found that in ecommerce industry, the perception of the logistic partner for Pharmacy Supply Chain management for ecommerce. This paper considers the all factor for decision making of courier service provider. The ranking result by TOPSIS pointed out that the first alternative is strategically optimum supplier.

\section{Journal Papers:}

\section{REFERENCES}

[1] ERDAL ÇAKIR, ÖZALP VAYVAY, logistics outsourcing and selection of third party logistics service provider (3PL) via fuzzy AHP, ISTANBUL, 2009,50-81,(31)

[2] Langley, C.J., Dort, E. v., Ross, T., Topp, U., Sykes, S.R., Strata, R. \& Dengel, T.2006. Third-Party logistics: results and findings for the 11th annual study.

\section{Books:}

[3] Sunil Chopra, Peter Meindl, Supply Chain Management (5th Edition (February 5, 2012).

\section{Chapters in Books:}

[4] Saaty, T.L., 2001. Decision making in complex environments: the analytic network process for decision making with dependence and feedback. RWS Publications, USA.

\section{Theses:}

[5] Y. J. Lai, T. Y. Liu and C. L. Hwang, TOPSIS for MODM, European Journal of Operational Research, vol.76, pp.486-500, 1994.

[6] G. R. Jahanshahloo, F. Hosseinzadeh Lotfi and A. R. Davoodi, Extension of TOPSIS for decision-making problems with interval data: interval efficiency, Mathematical and Computer Modeling, vol.49, pp.1137-1142, 2009

\section{Proceedings Papers:}

[7] Prendergast G., Pitt L., 1996, Packaging, marketing, logistics and the environment: are there trades-offs, International Journal of Physical Distribution \&Logistics Management, 26(6), 60-72.

[8] Da Silvera G.J.C., 2012, towards a framework for Operations management in e-commerce, International Journal of Operations \& Production Management, 23(2), 200-212.

[9] D.Agrawal, R. P. Agrawal, J. B. Singh and S. P. Tripathi, “E-commerce: True Indian Picture”, Journal of Advances in IT, vol. 3, no. 4, (2012), pp. 250-257. 